\title{
PENGOLAHAN LIMBAH PERTANIAN JERAMI DALAM PEMBUATAN KOMPOS
}

\author{
Al Rozzak Noer Ikhsan ${ }^{1}$, Alfian Muhammad Ramadhan ${ }^{2}$, Triana Yulianti ${ }^{3}$, \\ Yuliana Marta Dinata ${ }^{4}$ Marjuki Zulziar ${ }^{5}$ \\ Prodi Teknik Industri, Falkutas Teknik Universitas Pamulang Tangerang, Banten, Indonesia \\ ${ }^{1}$ trianayulianti01@gmail.com ${ }^{2}$ Alrozzak1928@gmail.com ${ }^{3}$ alfianmr0234@gmail.com \\ ${ }^{4}$ odachimartadinata@gmail.com ${ }^{5}$ dosen01775@unpam.ac.id
}

\begin{abstract}
ABSTRAK
Dilakukan Pengabdian Kepada Masyarakat sebagai salah satu langkah dilakukan dalam mengolah limbah jerami menjadi pupuk Kompos yang dibuat oleh tim Pengabdian Kepada Masyarakat sisa-sisa jerami milik anggota Kelompok Tani yang rencananya akan dibakar. Kegiatan ini diikuti oleh Kelompok Tani Barokah dan didampingi oleh staf Balai Penyuluhan Pertanian Desa Pagedangan Udik, Kecamatan Kronjo. Kegiatan ini bertujujan untuk peningkatan pengetahuan dan keterampilan masyarakat dalam mengolah limbah jerami menjadi pupuk kompos. disimpulkan bahwa dari keseluruhan peserta yang memberikan tanggapan ada sekitar 60\% sudah cukup memahami materi yang disampaikan, Pada instrument kuesioner kedua, ada sekitar $10 \%$ yang cukup setuju $10 \%$ setuju dan $80 \%$ sangat setuju. Dengan penyuluhan 5 ton/ha mampu menurunkan penggunaan pupuk anorganik $\mathrm{KCl}$ sebanyak 50\% dari jumlah kebutuhan pupuk tanpa penggunaan bahan organik. Hal ini memberikan hal baru untuk petani, Keberlanjutan program dapat berjalan ketika tingkat kesadaran masyarakat tani tinggi, serta didukung dan difasilitasi oleh Balai Penyuluhan Pertanian Desa Pagedangan Udik, Kecamatan Kronjo.
\end{abstract}

Kata kunci: Kompos, Petani, Pupuk Organik, Padi

\begin{abstract}
Community Service is carried out as one of the steps taken in processing straw waste into compost made by the Community Service team. This activity was attended by the Barokah Farmers Group and accompanied by staff from the Agricultural Extension Center in Pagedangan Udik Village, Kronjo District. This activity aims to increase the knowledge and skills of the community in processing straw waste into compost. it was concluded that of the overall participants who gave responses there were around $60 \%$ that they understood the material presented enough. In the second questionnaire instrument, there were about $10 \%$ who quite agreed, $10 \%$ agreed and $80 \%$ strongly agreed. The extension of 5 tons/ha was able to reduce the use of inorganic $\mathrm{KCl}$ fertilizer by $50 \%$ of the total fertilizer requirement without the use of organic matter. This provides new things for farmers. The sustainability of the program can run when the level of awareness of the farming community is high, and is supported and facilitated by the Agricultural Extension Center in Pagedangan Udik Village, Kronjo District.
\end{abstract}

Keywords: Compost, Farmers, Organic Fertilizer, Rice 


\section{PENDAHULUAN}

Kecamatan Kronjo merupakan salah satu wilayah Kabupaten Tangerang yang memiliki lahan pertanian yang cukup luas. Desa atau yang lebih dikenal dengan sebutan pagedangan udik Tangan merupakan salah satu yang terletak di Kecamatan kronjo. Dilihat dari topografi wilayah, kronjo berada pada lokasi Hamparan Kelompok Tani Jembatan sudah beberapa tahun belakangan ini hanya dapat ditanami padi setahun sekali (IP 100), sedangkan di musim kedua biasanya ditanami timun suri atau komoditas lain.dan drainase yang baik maka banyak lahan persawahan di hampir seluruh bagian kronjo (Dinas Pertanian Kabupaten Tangerang, 2021). Hal ini menunjukkan bahwa sebagian besar masyarakat bekerja sebagai petani. Menurut data dari Dinas KB, Capil, dan Kependudukan tangerang, Hal ini dikarenakan pada musim tanam kedua biasanya debit air sungai berkurang dan air laut (air asin) naik sehingga tidak dapat dimanfaatkan untuk mengairi persawahan, Sebagai informasi bahwa Dinas Pertanian dan Ketahanan Pangan Kabupaten Tangerang sudah menyalurkan Bantuan Benih Padi kepada 4 Kelompok Tani di Desa Pagedangan udik sebanyak 3.250 Kg dari Tanggal 9 - 11 Mei 2021 (menjelang lebaran). Hasil panen padi yang berlimpah di kronjo tidak hanya mendatangkan keuntungan bagi masyarakatnya, namun juga menjadi permasalahan karena adanya sisa panen padi berupa jerami serta sekam padi yang banyak menumpuk di penggilingan, di pinggir-pinggir sawah, dan di lahan setelah panen.

Pupuk kompos merupakan merupakan salah satu pupuk organik yang dibuat dengan cara menguraikan sisa-sisa tanaman dan hewan dengan bantuan organisme hidup. Untuk membuat pupuk kompos diperlukan bahan baku berupa material organik dan organisme pengurai yang berupa mikro dan makro organisme. Teknologi pengomposan dikembangkan dari proses penguraian material organik yang terjadi di alam bebas. Terbentuknya humus di hutan merupakan salah satu contoh pengomposan secara alami. Prosesnya berjalan sangat lambat, bisa sampai berbulan-bulan hingga bertahun-tahun (Rahmawanti dan Dony, 2014).

Masyarakat petani di Desa Pagedangan Udik belum mampu memanfaatkan limbah jerami karena minimnya pengetahuan, kesadaran, dan keterampilan untuk mengolah limbah jerami menjadi pupuk kompos. Dengan demikian dibutuhkan upaya untuk memberikan edukasi kepada masyarakat tani agar mampu mengolah limbah jerami menjadi pupuk kompos. 
Salah satu stakeholders yang terkait dengan pembangungan masyarakat adalah mahasiswa perguruan tinggi. Universitas Pamulang sebagai kampus di Indonesia mendukung program-program pengembangan masyarakat melalui Program Kuliah pengabdian kepada masyarakat. Program ini bertujuan untuk memberikan pengetahuan, pelatihan, dan pendampingan kepada masyarakat tani dalam mengolah limbah pertanian terutama jerami menjadi pupuk kompos. dengan adanya kegiatan ini, diharapkan masyarakat tani di di Desa Pagedangan Udik dapat memanfaatkan limbah hasil pertanian sebagai bahan baku dalam pembuatan pupuk kompos, sehingga masyarakat dapat mengurangi tingkat pencemaran lingkungan yang disebabkan oleh pembakaran jerami.

\section{METODE PELAKSANAAN}

Pelaksanaan kegiatan pengolahan jerami menjadi pupuk kompos dilaksanakan pada tanggal 15-16 Oktober 2021. Kegiatan dilaksanakan oleh 4 orang mahasiswa pengabdian kepada masyarakat Di Desa Pagedangan Udik, Kecamatan Kronjo Kabupaten Tangerang Provinsi Banten yang bertempat di salah satu kebun milik anggota kelompok tani di desa pagedangan udik melalui rangkaian kegiatan, yaitu:
1. Sosialisasi manfaat pengolahan jerami menjadi pupuk kompos;

2. Persiapan alat dan bahan yang digunakan dalam pengolahan limbah jerami;

3. Praktik pembuatan pupuk kompos dari jerami;

4. Monitoring dan evaluasi kegiatan.

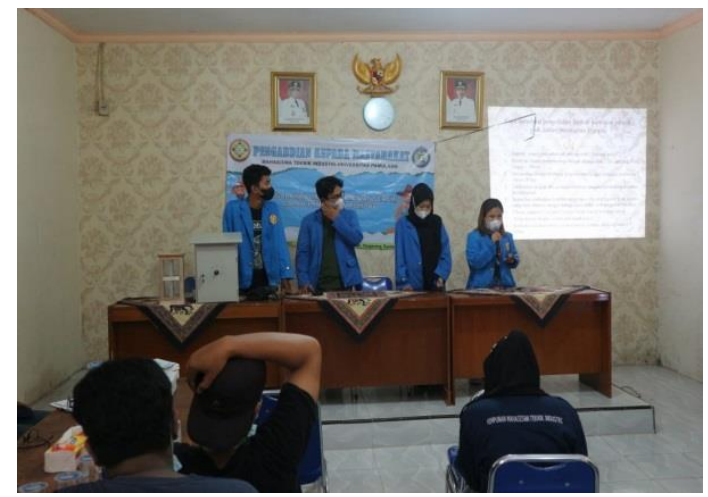

Gambar 1 .Penyuluhan PKM

Alat dan bahan yang digunakan antara lain adalah jerami, pupuk kandang, sekam, pupuk cair Em4, Air bersih (1 ember cat), Air nanas, (1 botol aqua besar), Air gula merah dan gula pasir (1 botol aqua besar). Tahapan pembuatan dimulai dari persiapan bahan-bahan yang akan digunakan, seperti pengecilan ukuran jerami dengan cara dipotong- potong menggunakan parang. Pemotongan jerami menjadi ukuran yang lebih kecil dilakukan oleh mahasiswa pengabdian kepada masyarakat bersamasama dengan anggota Kelompok Tani . Selanjutnya pelarutan, pupuk cair Em4. dengan perbandingan Air bersih (1 ember cat) untuk di campurkan dengan sekam. 
Tahapan berikutnya yaitu penyusunan tumpukan dengan dasar tumpukan berupa pupuk. kemudian diatasnya diberi tumpukan jerami, kemudian disiram dengan larutan pupuk cair Em4. Proses penumpukan tersebut dilakukan sebanyak empat tumpukan. Selanjutnya tumpukan dibungkus rapat dengan plastik agar tidak ada udara yang masuk. Tumpukan dibiarkan selama satu minggu, kemudian dilakukan proses pembalikan. Pembalikan dilakukan sampai kompos tercampur sempurna. Kompos ini siap dipanen dalam waktu kurang lebih 40 hari dengan proses pembalikan dilakukan seminggu sekali.

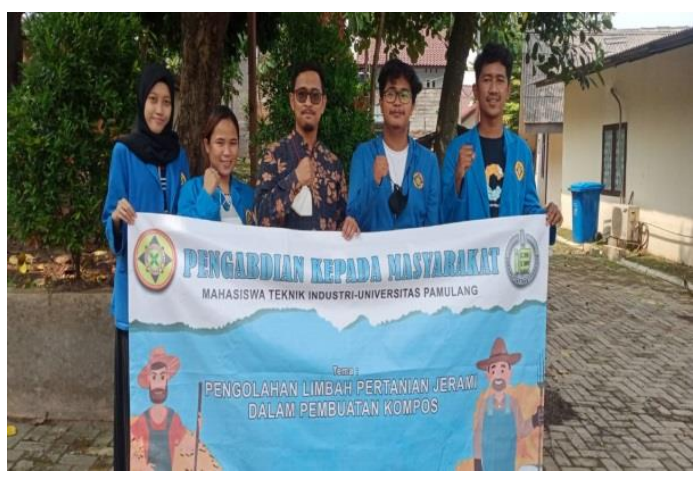

Gambar 2 .Tim PKM

Dengan langkah-langkah dalam proses pelaksanaan pengabdian kepada masyarakat diatas sebagai urutan dalam proses Limbah Pertanian Jerami Dalam Pembuatan Kompos dengan penerapan teknologi sederhana untuk pembekalan usaha kecil menengah di Desa Pagedangan Udik Kecamatan Kronjo, Kabupaten Tangerang Untuk lebih mudahnya dalam mengatasi permasalahan dan tidakan yang digunakan dalam penelitian dan pengabdian ini maka kerangka berfikir dibuat sebaga berikut:

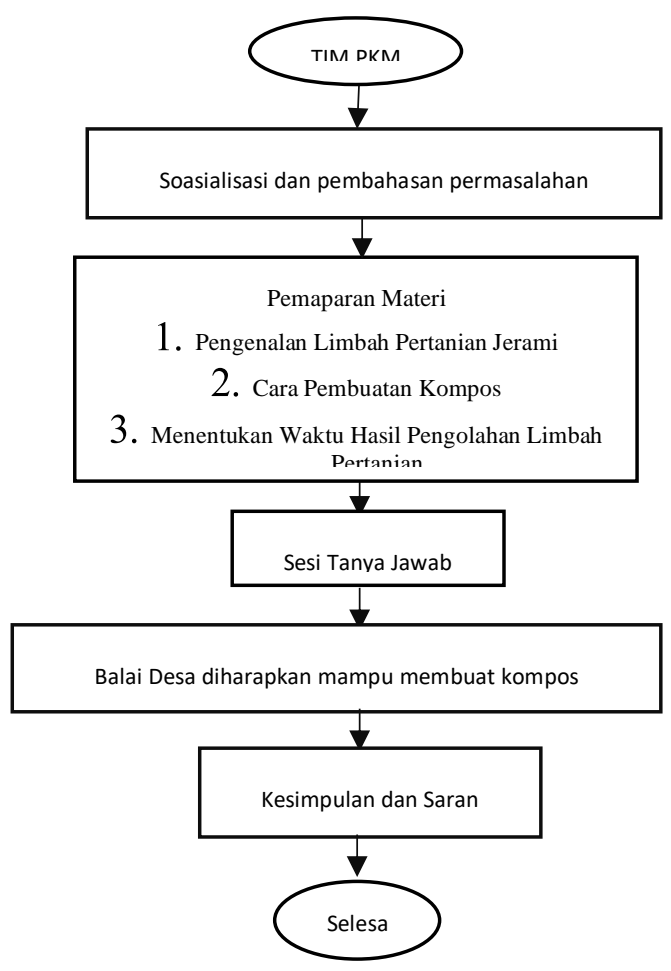

Gambar 3 Alur Proses Penelitian dan PKM

\section{HASIL DAN PEMBAHASAN}

Kompos yang dibuat oleh tim Pengabdian Kepada Masyarakat memanfaatkan sisasisa jerami milik anggota Kelompok Tani yang rencananya akan dibakar. Hasil yang diperoleh dalam pembuatan pupuk kompos ini belum sepenuhnya dapat diamati karena waktu pelaksanaan Pengabdian Kepada Masyarakat telah selesai. Dengan demikian, kegiatan pembuatan pupuk kompos ini hanya sampai pada proses pembalikan pupuk yang ketiga. Sebelum proses pembalikan kompos yang pertama diperoleh hasil yang masih sama dengan 
kondisi awal saat proses pembuatan, dengan kondisi penyimpanan agak basah karena pada saat itu turun hujan.

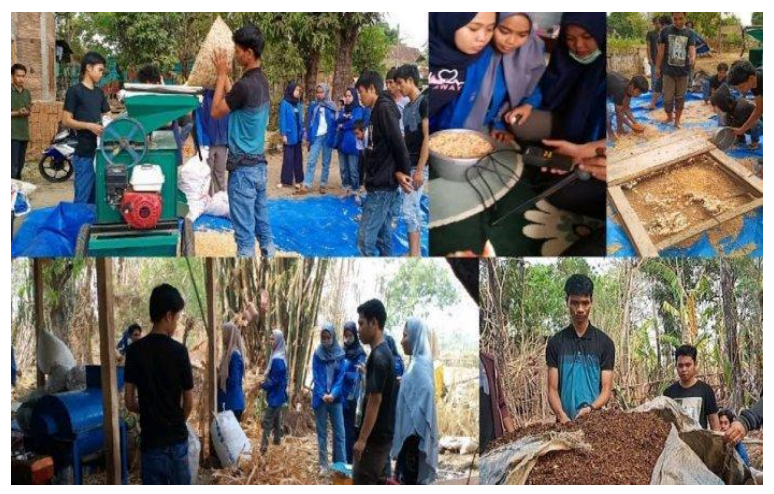

Gambar 4. Proses Pembuatan Kompos

Kemudian dilakukan proses pembalikan pertama agar semua bahan tercampur dan ditutup kembali. Seminggu kemudian, sebelum proses pembalikan yang kedua, kondisi jerami sudah sedikit kering dan ditemukan beberapa cendawan putih yang diduga dari Trichoderma sp. pertanda dekomposer sudah bekerja dan kondisi jerami sudah mulai hancur. Kemudian dilakukan pembalikan kedua dan ditutup. Keadaan kompos sebelum pembalikan yang ketiga, hampir sama dengan saat pembalikan yang kedua dengan kondisi jerami yang sudah hancur dan menyatu dengan bahan yang lainnya serta juga ditemukan cendawan-cendawan putih hasil dekomposisi dari Trichoderma sp. Kemudian dilakukan pembalikan ketiga dan ditutup kembali.

\section{a. Pemanfaatan Kompos Jerami sebagai Pupuk Organik}

Berdasarkan penelitian yang dilakukan oleh Rhofita (2016), penggunaan kompos jerami sebagai pupuk organik pada tanaman memberikan dampak sebagai berikut :

1. merupakan salah satu alternatif untuk substitusi penggunaan pupuk kimia. Kandungan hara jerami pada saat panen bergantung pada kesuburan tanah, kualitas dan kuantitas air irigasi, jumlah pupuk yang diberikan, dan musim/iklim.

2. Untuk menjaga kesuburan tanah pada sawah dan dapat menaikkan kandungan bahan orga nik tanah mengembalikan kesuburan tanah di sawah.

3. Penggunaan kompos jerami padi sebesar 5 ton/ha mampu menurunkan penggunaan pupuk anorganik $\mathrm{KCl}$ sebanyak $50 \%$ dari jumlah kebutuhan pupuk tanpa penggunaan bahan organik.

4. Untuk membantu memperbaiki karakteristik dan struktur tanah

5. Mampu membantu meningkatkan kualitas hasil panen

6. Kompos membantu meningkatkan daya serap air tanah 
b. Aspek Sosial, Ekonomi, dan

\section{Lingkungan}

Dilihat dari aspek ekonomi, pupuk kompos jerami memanfaatan bahanbahan organik yang berasal dari limbah pertanian terutama jerami yang mudah ditemui di sekitar masyarakat tani, sehingga pupuk ini tidak memerlukan biaya yang besar untuk bahan baku dalam proses pembuatannya. Dengan pemanfaatan pupuk kompos ini, dapat menghemat pengeluaran biaya lain untuk pembelian pupuk anorganik. Secara sosial, pemanfaatan pupuk kompos jerami dapat menimbulkan interaksi antara kelompok dan individu pelaku baik itu petani maupun penyuluh, yang sudah mengaplikasikan sistem usaha tani organik menjadi informasi penting yang bersifat kolektif. Secara kelembagaan bagi kelompok tani, pengalaman praktik bertani secara organik membantu menambah informasi mengenai sistem pertanian organik (Heryanto et al., 2016). Melalui program Pengabdian Kepada Masyarakat, masyarakat tani mendapatkan pengetahuan mengenai sistem pertanian organik yaitu penggunaan pupuk organik, salah satunya adalah pupuk kompos jerami. Dengan adanya pengetahuan dan kemampuan masyarakat tani dalam mengolah limbah jerami, masyarakat tani sadar akan manfaat pupuk kompos jerami sehingga dapat mengubah kebiasaan masyarakat agar tidak membakar jerami setelah musim panen. Manfaat pupuk kompos jerami berdasarkan aspek lingkungan yaitu mengurangi pencemaran lingkungan, dimana kebiasaan masyarakat tani yang membakar jerami dapat diminimalisir dengan melalukan pengolahan jerami menjadi pupuk kompos.

Pada pembahasan selanjutnya hasil dari pengabdian kepada masyarakat ini adalah selain memberikan ilmu dan bekal untuk berwirausaha kelompok Pengabdian Kepada Masyarakat juga memberikan produk Limbah Pertanian Jerami Dalam Pembuatan Kompos yang sudah jadi kepada para tani Desa Desa Pagedangan Udik Kecamatan Kronjo, Kabupaten Tangerang. 
Tabel 2 Hasil Kuesioner Tanggapan Peserta PKM

\begin{tabular}{llllll}
\hline \multicolumn{1}{c}{ Instrumen Kuesioner } & $\begin{array}{c}\text { Tidak } \\
\text { Setuju }\end{array}$ & $\begin{array}{c}\text { Kurang } \\
\text { Setuju }\end{array}$ & $\begin{array}{l}\text { Cukup } \\
\text { Setuju }\end{array}$ & $\begin{array}{c}\text { Setuju } \\
\text { Sangat } \\
\text { Setuju }\end{array}$ \\
\hline $\begin{array}{l}\text { Sosialisasi dan peneliti kepada } \\
\text { kelompok tani tentang pengolahan } \\
\text { Jerami Padi menjadi kompos }\end{array}$ & 2 & 2 & 6 \\
\hline Kemampuan komunikasi penyuluh & 1 & 1 & 1 & 7 \\
\hline $\begin{array}{l}\text { Evaluasi umum terhadap hasil } \\
\text { pelatihan pengolahan Jerami Padi }\end{array}$ & & 1 & 1 & 8 \\
menjadi kompos & & & & \\
(Sumber: Hasil Pengolahan Data) & & & & \\
\end{tabular}

Dari data tanggapan peserta Pengabdian Kepada Masyarakat pada table 2 di atas bisa disimpulkan bahwa dari keseluruhan peserta yang memberikan tanggapan ada sekitar $60 \%$ sudah cukup memahami materi yang disampaikan. Data lengkapnya bisa dilihat pada pie diagram berikut ini:

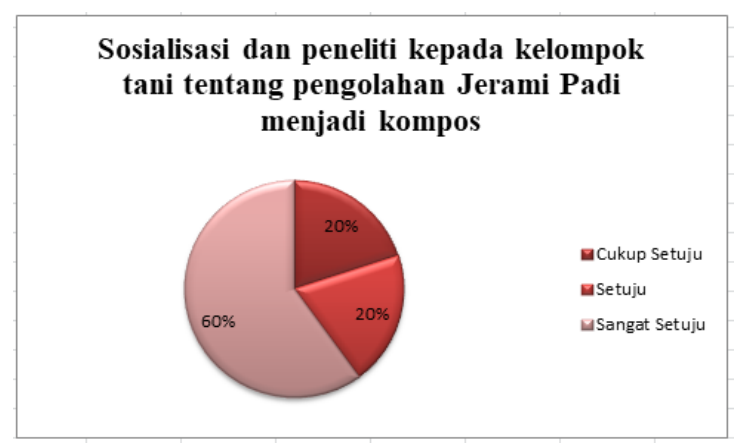

(Sumber: Hasil Pengolahan Data)

Gambar 5 Tanggapan Intrumen Kuesioner Pertama

Selanjutnya untuk instrument kuesioner kedua, ada sekitar $10 \%$ yang cukup setuju, $10 \%$ setuju dan $70 \%$ sangat setuju Kurang Setuju $10 \%$ yang perpendapat bahwa Penyuluhan yang diberikan sesuai dengan kebutuhan peserta Pengabdian Kepada Masyarakat. Data lengkapnya

bisa dilihat pada pie diagram berikut ini:

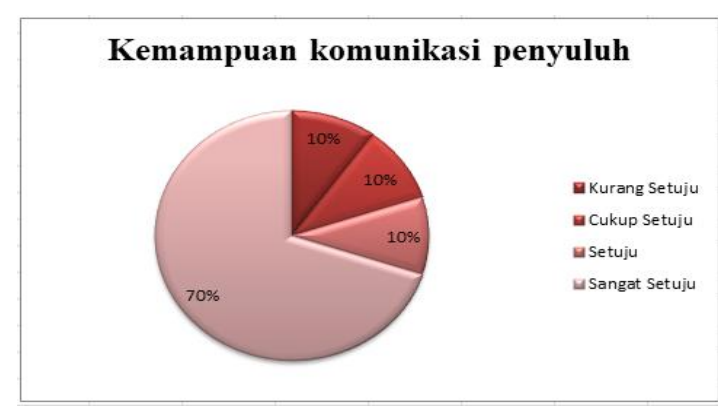

(Sumber: Hasil Pengolahan Data)

Gambar 6 Tanggapan Intrumen Kuesioner Kedua

Pada instrument kuesioner ketiga, ada sekitar $10 \%$ yang cukup setuju $10 \%$ setuju dan $80 \%$ sangat setuju yang perpendapat bahwa perlu diadakan pelatihan yang. Data lengkapnya bisa dilihat pada pie diagram berikut ini: 


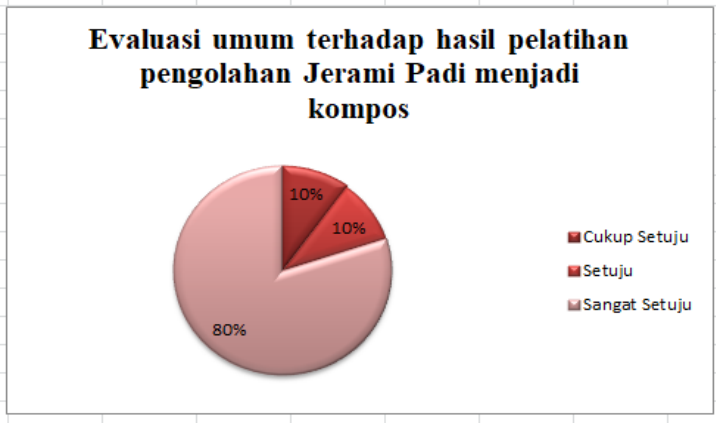

(Sumber: Hasil Pengolahan Data)

Gambar 7 Tanggapan Intrumen Kuesioner Ketiga

\section{KESIMPULAN DAN SARAN}

\section{A. Kesimpulan}

Program pengolahan limbah jerami di desa pagedangan udik kecamatan kronjo kabupaten Tangerang provinsi banten yang merupakan Program pengabdian kepada masyarakat UNPAM berjalan dengan baik, meskipun terdapat beberapa kendala. Salah satu kendala adalah sering hujan sehingga proses pelapukan jerami menjadi pupuk kompos membutuhkan waktu yang lebih lama daripada umumnya. Hasil yang telah dicapai adalah masyarakat tani mendapatkan pengetahuan mengenai manfaat kompos jerami dan langkahlangkah dalam mengolah limbah jerami menjadi pupuk organik. Dengan pemanfaatan pupuk kompos ini, dapat menghemat pengeluaran biaya lain untuk pembelian pupuk anorganik. Secara sosial, pemanfaatan pupuk kompos jerami dapat menimbulkan interaksi antara kelompok dan individu pelaku baik itu petani maupun penyuluh, yang sudah mengaplikasikan sistem usaha tani organik menjadi informasi penting yang bersifat kolektif. Penggunaan kompos jerami memberikan manfaat pada aspek ekonomi, sosial, lingkungan, serta agronomi yaitu perbaikan kualitas dan kuantitas tanah dan tanaman. Pemanfaatan limbah jerami diharapkan dapat mengubah kebiasaan masyarakat tani sehingga mampu mengurangi pencemaran lingkungan, yaitu pembakaran jerami.

\section{B. Saran}

Sebaiknya masyarakat mulai beralih menggunakan pupuk kompos untuk pemumpukan tanaman agar mengurangi pencemaran lingkungan akibat penggunaan pupuk kimia dapat meningkatkan produktivitas tanaman padi di Desa Pagedangan Udik.

\section{DAFTAR PUSTAKA}

Harahap, R., Gusmeizal, G., \& Pane, E. (2020). Efektifikatas Kombinasi Pupuk Kompos Kubis-Kubisan (Brassicaceae) dan Pupuk Organik Cair Bonggol Pisang terhadap Produksi Kacang Panjang (Vigna Sinensis L.). Jurnal Ilmiah 
Pertanian (JIPERTA), 2(2), 135143.

Widodo, K. H., \& Kusuma, Z. (2018).

Pengaruh kompos terhadap sifat fisik tanah dan pertumbuhan tanaman jagung di inceptisol. Jurnal Tanah dan Sumberdaya Lahan, 5(2), 959-967.

Kaya, E. (2018). Pengaruh kompos jerami dan pupuk NPK terhadap Ntersedia tanah, serapan-N, pertumbuhan, dan hasil padi sawah (Oryza Sativa L). Agrologia, 2(1). Ekawandani, N. (2019). Efektifitas Kompos Daun Menggunakan EM4 dan

Kotoran Sapi. Jurnal

TEDC, 12(2), 145-149.

Sutrisno, E., \& Priyambada, I. B. (2019).

Pembuatan pupuk kompos padat

limbah kotoran sapi dengan metoda fermentasi menggunakan bioaktivator starbio di Desa UjungUjung Kecamatan Pabelan Kabupaten Semarang. Jurnal Pasopati: Pengabdian Masyarakat dan Inovasi Pengembangan

Teknologi, 1(2).

Luta, D. A., Sitepu, S. M. B., \& Harahap, A. S. (2020). Pemanfaatan Kompos Dalam Pembudidayaan Bawang Merah Pada Pekarangan Rumah Di Desa Tomuan Holbung Kecamatan Bandar Pasir
Mandoge. JURNAL PRODIKMAS

Hasil Pengabdian Kepada

Masyarakat, 5(1), 32-35.

Rakun, A., \& Mertha, I. G. (2018). Pengaruh Kompos Terhadap Hasil Panen Tomat (Lycopersicum esculentum Mill). Jurnal Pijar Mipa, 13(1), 56-59.

Sahputra, H., Suswati, S., \& Gusmeizal, G. (2019). Efektivitas aplikasi kompos kulit kopi dan Fungi mikoriza arbuskular terhadap produktivitas jagung manis. Jurnal Ilmiah

Pertanian (JIPERTA), I(2), 102-112.

Safitri, I. N., Setiawati, T. C., \& Bowo, C. (2018). Biochar dan kompos untuk peningkatan sifat fisika tanah dan efisiensi penggunaan air. Techno: Jurnal Penelitian, 7(01), 116-127.

Putri, D. P. S., Bakti, P., Supono, I., Zulziar, M., \& Wibowo, P. (2020). Optimalisasi Penjualan Online Untuk Kelompok Usaha Konvensional Di Kelurahan Bojong, Kecamatan Pondok Terong, Depok. Abdi Laksana: Jurnal Pengabdian Kepada Masyarakat, 1(3), 388-394. Bastuti, S., Alfatiyah, R., Zulziar, M., \& Sugiyanto, S. (2021). RANCANG BANGUN TEKNOLOGI 
Filterisasi Air Kotor Menjadi Air

Bersih Memanfaatkan Teknlogi

Ultrafilterisasi Dan Ro. JITMI

(Jurnal Ilmiah Teknik dan

Manajemen Industri), 4(1), 46-

50. 